\title{
Effects of spermine supplementation on blood biochemical parameters, amino acid profile and ileum expression of amino acid transporters in piglets
}

\author{
T. Fang ${ }^{1,2}$, G. Jia ${ }^{1,2}$, H. Zhao ${ }^{1,2}$, X. Chen ${ }^{1,2}$, C. Wu', ${ }^{1,2}$ B. Xue ${ }^{1,2}$, J. Cai ${ }^{1,2}$, G. Tian ${ }^{1,2}$, \\ J. Wang ${ }^{3}$ and G. Liu ${ }^{1,2,4}$ \\ Sichuan Agricultural University, \\ ${ }^{1}$ Institute of Animal Nutrition, ${ }^{3}$ Maize Research Institute, Chengdu 611130, Sichuan, China \\ ${ }^{2}$ Key Laboratory for Animal Disease-Resistance Nutrition of China Ministry of Education, Chengdu 611130, Sichuan, China
}

KEY WORDS: amino acids, amino acid transporters, biochemical parameters, ileum, piglets, spermine

Received: 21 February 2017

Revised: 7 October 2019

Accepted: 12 December 2019

${ }^{4}$ Corresponding author:

e-mail: 457127727@qq.com

\begin{abstract}
The effects of spermine supplementation and extended spermine supplementation on blood biochemical parameters, serum amino acid profile and ileum expression of amino acid transporters in piglets were examined in this study. Piglets were fed adequate nutrient intake supplemented or not with spermine ( $0.4 \mathrm{mmol} / \mathrm{kg}$ body weight) for $7 \mathrm{~h}$ or 3, 6 or 9 days. Spermine supplementation significantly increased aspartate aminotransferase activity and albumin content, but decreased triglyceride level in serum $(P<0.05)$. There was a significant increase in levels of arginine, histidine, isoleucine, leucine, threonine, valine, alanine, asparagine, serine, proline, taurine and tyrosine $(P<0.05)$ in the spermine-treated groups. Spermine significantly increased the mRNA levels of SLC1A1, SLC1A5, SLC7A1, SLC7A7, SLC7A9, SLC5A1, SLC6A19 and $S L C 15 A 1$ in ileum $(P<0.05)$. The extended spermine supplementation exerted different effects on the blood biochemical parameters, amino acid profile and ileum expression of amino acid transporters in comparison to the 7 -h group $(P<0.05)$. In summary, spermine supplementation can affect biochemical parameters and amino acid profile in serum and may enhance the ileum absorption of amino acids by increasing the expression of amino acid transporters in piglets.
\end{abstract}

\section{Introduction}

Spermine is a representative of a group of aliphatic organic polycations, known as 'polyamines', and is found in nearly all tissues and cells as a lowmolecular-weight molecule (Hougaard et al., 1986). Spermine plays various physiological functions and is essential for stimulation of cell proliferation and differentiation, synthesis of DNA, RNA and proteins, acceleration of immune response, prevention of organism from oxidative toxicity, modulation of cell membrane transport functions, interaction with various intracellular messengers, and modification of organic development (Pegg, 2014). Supplementation with an appropriate dose of spermine is correlated with the biochemical and physiological changes in the blood. Spermine affects glucose and protein metabolism by increasing glucose and triglyceride levels and decreasing blood urea nitrogen trend in rats (Liu et al., 2014a). However, no information is available on the effects of spermine supplementation and time of its duration on the changes in clinical chemistry in pigs. In addition to blood biochemical parameters, blood concentrations of amino acids 
and their products are important factors that are required for maintaining whole-body homeostasis (Wu, 2009). Amino acids are building blocks for tissue proteins and essential substrates for the synthesis of many low molecular-weight substances (e.g., polyamines) with enormous physiological importance (Wu, 2010). Dietary supplementation with arginine (that is, as an upstream product of spermine) can increase plasma arginine and ornithine concentrations but decrease those of lysine and histidine (Southern and Baker, 1982). However, the relationship between spermine supplementation and time of such supplementation, and blood concentrations of amino acids remains largely unknown.

Furthermore, amino acids in the blood are transported into the cell in the free form by specific transporters. Amino acid transporters are secondary transporters involved in the nutrients ingesting, mediating the transfer of amino acids and regulating ionic homeostasis between different cells and organs (Closs et al., 2006). There are 6 major families of amino acid transporters in the solute carrier (SLC) gene superfamily (SLC1, SLC6, SLC7, SLC36, $S L C 38$ and SLC43 families) and an orphan SLC16 monocarboxylate transporter, which transports aromatic amino acids (Taylor, 2014). These transporters mediate amino acids exchange between extracellular and intracellular fluid compartments, delivering substrates to intracellular amino acid sensors. In a recent metabolomic study it was found that spermine supplementation can partially change the metabolites of the amino acids in the ileum of rats increasing the ileum levels of glutamate, glutamine, methionine, taurine and threonine but decreasing the level of lysine (Liu et al., 2015). These changes in amino acid metabolic profile in ileum may be associated with amino acid transporters presence in this part of the small intestine. However, no research is available on the effects of spermine supplementation and its extended duration on the expression of intestinal amino acid transporters in pigs.

The previous study suggests that an excessive dose of spermine usually significantly inhibits cell growth (Larqué et al., 2007). Hence, the spermine dosage and time of spermine supplementation in the present experiment were set according to prior experiments (Cheng et al., 2006; Cao et al., 2015), which indicated that low or optimum dose of spermine exerts excellent effects on the organs. The present study is part of a large study on the effects of spermine supplementation on intestinal development and serum antioxidant status in suckling piglets (Fang et al., 2016). The aim of this study is to investigate the effects of appropriate levels of spermine supplementation and extended spermine supplementation on blood biochemical parameters, amino acid profile in serum and expression of amino acid transporters in the ileum of piglets. The results of this study can provide a theoretical basis for the development of spermine as a functional ingredient in feeds.

\section{Material and methods}

\section{Animal experiment and sample collection}

Animal experimental procedures followed the actual law of animal protection and was approved by the Animal Care and Use Committee of Sichuan Agricultural University (China). All protocols were performed in accordance with the guidelines of the National Research Council's Guide for the Care and Use of Laboratory Animals.

Eighty piglets [Duroc $\times($ Landrace $\times$ Yorkshire $)$ ] were weaned at day 12 of age with a body weight (BW) of $3.3 \pm 0.3 \mathrm{~kg}$, and housed in individual metabolic cages with trough and water tank $(0.8 \times$ $0.7 \times 0.4 \mathrm{~m})$. All piglets were randomly assigned to eight groups (10 piglets/group) as follows: C-7h, C-3d, C-6d, C-9d, S-7h, S-3d, S-6d, and S-9d. In four groups piglets had free access to formula milk for $7 \mathrm{~h}$ or 3,6 or 9 days with additional supplementation of spermine $(0.4 \mathrm{mmol} / \mathrm{kg} \mathrm{BW})$ once a day (S-7h, S-3d, S-6d and S-9d, respectively), in the corresponding control groups there was no spermine supplementation (C-7h, C-3d, C-6d and C-9d, respectively). The basic formula milk powder was prepared according to our previous study (Fang et al., 2016), and the milk formula contained cow's milk based powder (58\%), whey protein concentrate (25\%), casein $(5.7 \%)$, coconut oil $(10.0 \%), \mathrm{CaH}_{2} \mathrm{PO}_{4}$ $(0.1 \%)$, choline chloride $(0.1 \%)$, amino acids $(0.5 \%)$, minerals and vitamins $(0.6 \%)$. Formula milk was prepared to supply a similar composition of nutrients to sow milk. The milk was prepared by mixing $1 \mathrm{~kg}$ of formula powder ( $87.5 \%$ dry matter) with 41 of water.

Blood samples were collected into heparinized tubes by venipuncture in the morning (08:00) after overnight fasting at the end of the 7-h and 3-, 6- and 9-day feeding experiments (at this time, the piglets were $12,15,18$ and 21 days old, respectively). Whole blood samples were centrifuged at $3500 \mathrm{~g}$ for $10 \mathrm{~min}$ at $4{ }^{\circ} \mathrm{C}$, and then serum samples were frozen and stored at $-20{ }^{\circ} \mathrm{C}$ until analysis. Immediately after slaughtering, the ileum samples from each piglet were collected and quickly stored at $-80{ }^{\circ} \mathrm{C}$ until further analysis. 
Table 1. Primers for genes encoding amino acid transporters of ileum in piglets

\begin{tabular}{|c|c|c|c|c|c|}
\hline Genes & Primers & Sequence $\left(5^{\prime} \rightarrow 3^{\prime}\right)$ & Size, bp & $\mathrm{T}_{\mathrm{m}},{ }^{\circ} \mathrm{C}$ & Accession no. \\
\hline \multirow[t]{2}{*}{$\overline{S L C 1 A 1}$} & Forward & TTCTTTGTTCCCCACATCTTTCTT & 68 & 58 & NM_001164649.1 \\
\hline & Reverse & СССТTСССАСАСТСGАСТGА & & & \\
\hline \multirow[t]{2}{*}{ SLC1A5 } & Forward & CCCGGACCTAGCCTCTTGA & 57 & 58 & XM_003127238.4 \\
\hline & Reverse & GGTCCTTGGCTCCGAAAAG & & & \\
\hline \multirow[t]{2}{*}{ SLC7A1 } & Forward & CATCTTTGCCGTGATCATAATTCT & 79 & 58 & NM_001012613.1 \\
\hline & Reverse & TTTGTTGACCATGGCTGACTCT & & & \\
\hline \multirow[t]{2}{*}{ SLC7A7 } & Forward & TTTGGTTCCCAAGGTTGCA & 58 & 58 & NM_001110421.1 \\
\hline & Reverse & GCAGCTTCCTGGCATTGC & & & \\
\hline \multirow[t]{2}{*}{ SLC5A1 } & Forward & TGGCCTGAGACCCTCCTTCT & 71 & 58 & NM_001164021.1 \\
\hline & Reverse & CATCAATCAAGACACCTCAAAAAAA & & & \\
\hline \multirow[t]{2}{*}{ SLC6A19 } & Forward & GCAACGTGACGCAGGAGAA & 57 & 58 & XM_003359855.3 \\
\hline & Reverse & GGTCGGAGGCGTTGCA & & & \\
\hline \multirow[t]{2}{*}{ SLC7A9 } & Forward & TTGCCATCATCTGTCTCAGCTT & 62 & 58 & EF127857.1 \\
\hline & Reverse & GCTGCAGCCTGCGTAGAAG & & & \\
\hline \multirow[t]{2}{*}{ SLC15A1 } & Forward & ACTGCAAGCAACGACCATGA & 61 & 58 & NM_214347.1 \\
\hline & Reverse & CATCTGATCCGGCTGGATTT & & & \\
\hline \multirow[t]{2}{*}{ ACTB } & Forward & TGCGGGACATCAAGGAGAA & 58 & 58 & DQ452569.1 \\
\hline & Reverse & GCCATCTCCTGCTCGAAGTC & & & \\
\hline
\end{tabular}

Analyses of biochemical parameters in serum

Biochemical parameters including glucose (GLU), total cholesterol (CHO), triglyceride (TG), total protein (TP), albumin (ALB), blood urea nitrogen (BUN) and creatinine (CRE) content and alanine aminotransferase (ALT) and aspartate aminotransferase (AST) activity were measured using an automatic biochemical analyser (AUTOLAB PM 4000; AMS Corporation, Rome, Italy).

\section{Measurement of amino acid profiles in serum}

Serum amino acid concentrations were determined using an amino acid analyser (Hitachi L-8800, Hitachi Corporation, Tokyo, Japan) as previously described by Rutherfurd and Gilani (2009). The amino acid profile included: arginine (Arg), histidine (His), isoleucine (Ile), leucine (Leu), lysine (Lys), methionine (Met), phenylalanine (Phe), threonine (Thr), valine (Val), alanine (Ala), asparagine (Asp), cystine (Cys), glutamate (Glu), glycine (Gly), serine (Ser), taurine (Tau), proline (Pro), ornithine (Orn), tyrosine (Tyr), urea and ammonia.

\section{Determination of mRNA expression of amino acid transporters in ileum}

Total RNA was extracted from frozen ileum segment using TRIzol Reagent (Takara, Dalian, China) according to the manufacturer's protocol. The $1 \%$ agarose gel electrophoresis was used to check the in- tegrity of obtained RNA samples. Subsequently, total RNA was used to synthesize cDNA using a PrimeScript $^{\mathrm{TM}}$ RT reagent kit with gDNA Eraser (Takara, Dalian, China) according to the manufacturer's instructions. Primer sequences of the corresponding amino acid transporters and $\beta$-actin $(A C T B)$ genes were summarized in Table 1 . The sequences of all primers were designed with use of the Primer Express Software (version 3.0; Applied Biosystems, Foster City, CA, USA) and synthesized by TaKaRa Biotechnology Company (Takara, Dalian, China). Realtime PCR was performed using the SYBR Green PCR reagent kit on Real-Time PCR instrument (ABI 7900HT, Applied Biosystems, Foster City, CA, USA). The reaction mixture $(8 \mu \mathrm{l})$ consisted of $4 \mu \mathrm{l}$ of SYBR Premix Ex Taq II with ROX Reference Dye, $0.8 \mu 1$ of cDNA, $10 \mu \mathrm{M}$ of forward primer $(0.8 \mu \mathrm{l})$ and reverse primer $(0.8 \mu \mathrm{l})$ and $1.6 \mu \mathrm{l}$ of $\mathrm{ddH}_{2} \mathrm{O}$. The thermal cycler conditions for PCR included a prerun at $95^{\circ} \mathrm{C}$ for $10 \mathrm{~s}$, forty-two cycles of denaturation step at $95^{\circ} \mathrm{C}$ for $10 \mathrm{~s}$, followed by a $58^{\circ} \mathrm{C}$ annealing temperature for $35 \mathrm{~s}$ and extension step at $72{ }^{\circ} \mathrm{C}$ for $15 \mathrm{~s}$. The relative target gene expression compared with the housekeeping $A C T B$ gene was analysed according to the $2^{-\triangle \triangle \mathrm{Ct}}$ method as described by Livak and Schmittgen (2001).

\section{Statistical analysis}

Data were analysed by employing two-way analysis of variance (ANOVA) using the general linear model procedure of SPSS ver. 22.0 (SPSS 
Inc., Chicago, IL, USA) after analysing for normality and homogeneity of variances using Shapiro-Wilk's W-test and Levene's test, respectively. The model included two main effects: spermine level (S: 0 or $0.4 \mathrm{mmol} / \mathrm{kg} \mathrm{BW}$ ) and treatment duration (T: $7 \mathrm{~h}$ or 3,6 or 9 days), and their interaction $(\mathrm{S} \times \mathrm{T})$. If at least one main effect or interaction was statistically significant, the differences between groups were identified using Duncan's multiple range test. All results were expressed as mean, and $P<0.05$ was considered as statistically significant. Pearson's correlation coefficients among the data were determined using the correlation analysis of SPSS.

\section{Results}

\section{Biochemical parameters in serum of piglets}

When spermine was supplemented for $7 \mathrm{~h}$ there was no difference between $\mathrm{C}-7 \mathrm{~h}$ and $\mathrm{S}-7 \mathrm{~h}$ groups in case of any examined biochemical parameter (Table 2). The 3-day spermine supplementation caused a decrease in TG content and AST/ALT ratio, but an increase in ALT activity, ALB and BUN contents, and BUN/CRE and ALB/TP ratios in comparison to $\mathrm{C}-3 \mathrm{~d}$ group $(P<0.05)$. In the 6-day experiment, the AST/ALT ratio and AST activity were higher in the $\mathrm{S}-6 \mathrm{~d}$ group in comparison to the C-6d one $(P<0.05)$, however, BUN/CRE ratio decreased. After 9 days of supplementation only BUN content was decreased in $\mathrm{S}-9 \mathrm{~d}$ group in comparison to $\mathrm{C}-9 \mathrm{~d}$ one $(P<0.05)$.

When the duration of supplementation was compared, it was stated that ALB and BUN contents were significantly increased in the 3-day spermine supplemented group than in the $7-\mathrm{h}$ one (S-7h vs S-3d; $P<0.05$ ) whereas there was no difference between C-7h and C-3d groups. Meanwhile, the 6-day spermine supplementation significantly decreased TG and ALT in comparison with 7-h spermine supplementation $(\mathrm{S}-7 \mathrm{~h}$ vs S-6d; $P<0.05)$ whereas there was no difference between $\mathrm{C}-7 \mathrm{~h}$ and $\mathrm{C}-6 \mathrm{~d}$ groups.

\section{Amino acid profiles in serum of piglets}

In comparison to C-7h group, the levels of Arg, His, Leu, Phe, Val, Asp, Pro, Ser, Tau and Tyr significantly increased but Cys significantly decreased in S-7h group (Table 3). In the 3-day groups spermine addition caused Arg, Thr, Asp, Glu and Tyr content increase whereas urea content was decreased in comparison to those in the C-3d group $(P<0.05)$. When the supplementation lasted for 6 days, Arg and Pro were significantly decreased in the S-6d group in comparison to $\mathrm{C}-6 \mathrm{~d}$ pigs $(P<0.05)$. In the 9-day experiment, Asp content was significantly increased in the $\mathrm{S}-9 \mathrm{~d}$ group than in the $\mathrm{C}-9 \mathrm{~d}$ one $(P<0.05)$.

Comparing the duration of supplementation, it was stated that in comparison to the $\mathrm{S}-7 \mathrm{~h}$ group, the 3-day spermine supplementation caused a decrease in His, Phe, Ile, Val, Ala and Ser contents, while in the control group (C-3d) the content of these amino acids was stable in comparison to the $\mathrm{C}-7 \mathrm{~h}$ group. The Cys content did not differ between S-3d and $\mathrm{S}-7 \mathrm{~h}$, whereas there was stated a decrease in the C-3d group in comparison to the $\mathrm{C}-7 \mathrm{~h}$ one. The contents of Lys, Thr, Pro and Tyr were decreased in 3-day experiment in comparison to $7-\mathrm{h}$ one regardless spermine addition. After 6 days of supplementation duration, Arg content was decreased in the S-6d group (in comparison to the $\mathrm{S}-7 \mathrm{~h}$ ), while in the control

Table 2. Effects of spermine supplementation (S) and time of its duration $(T)$ on the serum biochemical parameters in piglets ${ }^{1}$

\begin{tabular}{|c|c|c|c|c|c|c|c|c|c|c|c|c|}
\hline \multirow{2}{*}{ Indices } & \multicolumn{2}{|l|}{$7 \mathrm{~h}^{2}$} & \multicolumn{2}{|l|}{$3 d$} & \multicolumn{2}{|l|}{$6 \mathrm{~d}$} & \multicolumn{2}{|l|}{$9 d$} & \multirow{2}{*}{ SEM } & \multicolumn{3}{|l|}{$P$-value } \\
\hline & $\overline{C-7 h}$ & S-7h & $\overline{C-3 d}$ & $S-3 d$ & $\overline{C-6 d}$ & S-6d & $\overline{C-9 d}$ & $S-9 d$ & & $S$ & $T$ & $S \times T$ \\
\hline $\mathrm{GLU}, \mathrm{mmol} / \mathrm{l}$ & $6.68^{b}$ & $7.76^{\mathrm{bc}}$ & $8.27^{c}$ & $7.32^{\mathrm{bc}}$ & $4.68^{a}$ & $4.17^{a}$ & $4.32^{\mathrm{a}}$ & $4.24^{a}$ & 0.238 & 0.711 & $<0.001$ & 0.045 \\
\hline $\mathrm{CHO}, \mathrm{mmol} / \mathrm{l}$ & $3.96^{\mathrm{bc}}$ & $4.28^{c}$ & $4.08^{b c}$ & $3.66^{b}$ & $2.40^{a}$ & $2.25^{\mathrm{a}}$ & $2.52^{\mathrm{a}}$ & $2.44^{a}$ & 0.110 & 0.736 & $<0.001$ & 0.204 \\
\hline $\mathrm{TG}, \mathrm{mmol} / \mathrm{l}$ & $0.732^{\mathrm{abc}}$ & ${ }^{c} 0.833^{b c}$ & $2.09^{d}$ & $0.890^{\circ}$ & $0.694^{\mathrm{ab}}$ & $0.601^{a}$ & $0.764^{\mathrm{abc}}$ & $=0.740^{a b c}$ & 0.070 & $<0.001$ & $<0.001$ & $<0.001$ \\
\hline ALT, U/I & $37.5^{b c}$ & $38.3^{c}$ & $29.4^{\mathrm{a}}$ & $39.6^{c}$ & $30.6^{\mathrm{ab}}$ & $27.1^{\mathrm{a}}$ & $32.9^{a b c}$ & $38.5^{c}$ & 0.973 & 0.064 & 0.004 & 0.040 \\
\hline AST, U/I & $58.0^{\mathrm{ab}}$ & $66.5^{b c}$ & $76.7^{\mathrm{cd}}$ & $77.7^{\mathrm{cd}}$ & $48.0^{\mathrm{a}}$ & $70.1^{b c}$ & $77.6^{\mathrm{cd}}$ & $86.4^{\mathrm{d}}$ & 2.11 & 0.005 & $<0.001$ & 0.201 \\
\hline TP, g/l & $65.3^{c}$ & $61.7^{\mathrm{bc}}$ & $60.7^{\mathrm{ab}}$ & $61.7^{\mathrm{bc}}$ & $57.2^{\mathrm{a}}$ & $60.1^{\mathrm{ab}}$ & $57.6^{\mathrm{ab}}$ & $58.9^{a b}$ & 0.522 & 0.708 & 0.001 & 0.102 \\
\hline ALB, g/l & $34.0^{\mathrm{a}}$ & $32.7^{\mathrm{a}}$ & $32.5^{\mathrm{a}}$ & $58.8^{b}$ & $30.3^{a}$ & $32.1^{a}$ & $31.7^{\mathrm{a}}$ & $30.9^{a}$ & 1.15 & $<0.001$ & $<0.001$ & $<0.001$ \\
\hline BUN, mmol/l & $1.43^{a}$ & $1.35^{\mathrm{a}}$ & $1.87^{\mathrm{a}}$ & $4.11^{\mathrm{bcd}}$ & $4.72^{\mathrm{cd}}$ & $3.64^{\mathrm{bc}}$ & $4.82^{\mathrm{d}}$ & $3.53^{b}$ & 0.264 & 0.860 & $<0.001$ & 0.001 \\
\hline CRE, $\mu \mathrm{mol} / / \mathrm{l}$ & 100 & 87.3 & 94.1 & 137 & 96.2 & 96.1 & 94.8 & 113 & 5.29 & 0.260 & 0.467 & 0.266 \\
\hline AST/ALT & $1.52^{\mathrm{a}}$ & $1.72^{\mathrm{a}}$ & $2.84^{c}$ & $2.00^{\mathrm{ab}}$ & $1.78^{\mathrm{a}}$ & $2.47^{\mathrm{bc}}$ & $2.52^{\mathrm{bc}}$ & $2.05^{\mathrm{ab}}$ & 0.082 & 0.438 & 0.001 & 0.001 \\
\hline BUN/CRE & $0.012^{a}$ & $0.016^{a}$ & $0.016^{a}$ & $0.035^{b}$ & $0.052^{d}$ & $0.039^{b c}$ & $0.047^{c d}$ & $0.042^{\mathrm{bcd}}$ & 0.002 & 0.668 & $<0.001$ & $<0.001$ \\
\hline ALB/TP & $0.520^{\mathrm{a}}$ & $0.540^{\mathrm{a}}$ & $0.536^{a}$ & $1.00^{b}$ & $0.532^{\mathrm{a}}$ & $0.535^{\mathrm{a}}$ & $0.543^{a}$ & $0.534^{a}$ & 0.020 & $<0.001$ & $<0.001$ & $<0.001$ \\
\hline
\end{tabular}

${ }^{1}$ data are expressed as mean for ten piglets per treatment; ${ }^{2}$ groups: $7 \mathrm{~h}, 3 \mathrm{~d}, 6 \mathrm{~d}$ and $9 \mathrm{~d}$ - treatment duration: $7 \mathrm{~h}$ and 3,6 and 9 days, respectively; $\mathrm{C}$ - control (no spermine supplementation); $\mathrm{S}$ - spermine supplementation at a dose of $0.4 \mathrm{mmol} / \mathrm{kg}$ body weight; ${ }^{\mathrm{a}-\mathrm{d}}$ - means within different superscripts are significantly different $(P<0.05)$ 
Table 3. Effects of spermine supplementation (S) and time of its duration (T) on the serum amino acids profile in piglets ${ }^{1}$

\begin{tabular}{|c|c|c|c|c|c|c|c|c|c|c|c|c|}
\hline \multirow{2}{*}{ Indices } & \multicolumn{2}{|l|}{$7 h^{2}$} & \multicolumn{2}{|l|}{$3 d$} & \multicolumn{2}{|l|}{$6 \mathrm{~d}$} & \multicolumn{2}{|l|}{$9 d$} & \multirow{2}{*}{ SEM } & \multicolumn{3}{|c|}{$P$-value } \\
\hline & $\overline{C-7 h}$ & S-7h & $\overline{C-3 d}$ & S-3d & $\overline{C-6 d}$ & S-6d & C-9d & S-9d & & $S$ & $T$ & $S \times T$ \\
\hline \multicolumn{13}{|c|}{ Essential amino acids, $\mu \mathrm{mol} / /$} \\
\hline arginine & $45.4^{\mathrm{a}}$ & $93.0^{b}$ & $36.2^{\mathrm{a}}$ & $85.7^{b}$ & $101^{b}$ & $47.9^{\mathrm{a}}$ & $132^{c}$ & $155^{c}$ & 7.19 & 0.026 & $<0.001$ & $<0.001$ \\
\hline histidine & $27.7^{\mathrm{a}}$ & $65.4^{c}$ & $41.5^{\mathrm{ab}}$ & $31.0^{\mathrm{a}}$ & $72.2^{\mathrm{c}}$ & $81.4^{c}$ & $57.6^{\mathrm{bc}}$ & $77.3^{c}$ & 4.01 & 0.017 & $<0.001$ & 0.033 \\
\hline isoleucine & $185^{\mathrm{ab}}$ & $227^{\mathrm{b}}$ & $152^{\mathrm{a}}$ & $145^{\mathrm{a}}$ & $133^{a}$ & $167^{a}$ & $164^{a}$ & $164^{a}$ & 6.85 & 0.021 & 0.006 & 0.564 \\
\hline leucine & $179^{a}$ & $265^{b}$ & $186^{b}$ & $177^{\mathrm{b}}$ & $221^{\mathrm{ab}}$ & $265^{b}$ & $225^{\mathrm{ab}}$ & $247^{a b}$ & 9.11 & 0.004 & 0.052 & 0.294 \\
\hline lysine & $379^{b c}$ & $451^{c}$ & $250^{\mathrm{a}}$ & $262^{\mathrm{a}}$ & $224^{a}$ & $264^{\mathrm{a}}$ & $316^{\mathrm{ab}}$ & $323^{\mathrm{ab}}$ & 15.6 & 0.147 & $<0.001$ & 0.714 \\
\hline methionine & 131 & 141 & 127 & 123 & 100 & 123 & 89.0 & 109 & 6.95 & 0.120 & 0.187 & 0.816 \\
\hline phenylalanine & $83.3^{a}$ & $162^{\mathrm{d}}$ & $93.7^{\mathrm{ab}}$ & $104^{\mathrm{ab}}$ & $116^{\mathrm{abc}}$ & $105^{a b}$ & $144^{\text {cd }}$ & $124^{\mathrm{bc}}$ & 5.62 & 0.099 & 0.040 & 0.001 \\
\hline threonine & $567^{c d}$ & $654^{d}$ & $358^{b}$ & $504^{c}$ & $124^{\mathrm{a}}$ & $183^{a}$ & $316^{b}$ & $297^{b}$ & 31.4 & 0.004 & $<0.001$ & 0.082 \\
\hline valine & $319^{a}$ & $463^{b}$ & $331^{a}$ & $301^{a}$ & $361^{\mathrm{ab}}$ & $368^{\mathrm{ab}}$ & $398^{\mathrm{ab}}$ & $406^{\mathrm{ab}}$ & 13.7 & 0.031 & 0.206 & 0.131 \\
\hline \multicolumn{13}{|c|}{ Non-essential amino acids, $\mu \mathrm{mol} / \mathrm{l}$} \\
\hline alanine & $768^{\text {cd }}$ & $911^{d}$ & $668^{b c}$ & $689^{b c}$ & $418^{a}$ & $546^{\mathrm{ab}}$ & $464^{a}$ & $574^{\mathrm{ab}}$ & 31.4 & 0.006 & $<0.001$ & 0.602 \\
\hline asparagine & $52.6^{b}$ & $70.1^{c}$ & $33.4^{\mathrm{a}}$ & $48.9^{b}$ & $61.7^{\mathrm{bc}}$ & $48.8^{b}$ & $62.4^{\mathrm{bc}}$ & $84.8^{d}$ & 3.00 & 0.003 & $<0.001$ & 0.004 \\
\hline cystine & $45.8^{\mathrm{d}}$ & $24.1^{\mathrm{bc}}$ & $15.5^{\mathrm{ab}}$ & $25.9^{b c}$ & $10.3^{\mathrm{a}}$ & $7.33^{\mathrm{a}}$ & $27.5^{\mathrm{bc}}$ & $32.6^{c}$ & 2.36 & 0.511 & $<0.001$ & 0.007 \\
\hline glutamate & $242^{\mathrm{bc}}$ & $263^{b c}$ & $113^{a}$ & $201^{b c}$ & $272^{b c}$ & $266^{b c}$ & $303^{\mathrm{cd}}$ & $363^{d}$ & 14.1 & 0.115 & $<0.001$ & 0.099 \\
\hline glycine & 1311 & 1651 & 1259 & 1192 & 1042 & 1170 & 1370 & 1673 & 58.9 & 0.848 & 0.751 & 0.393 \\
\hline proline & $419^{c}$ & $500^{d}$ & $260^{a}$ & $315^{\mathrm{ab}}$ & $364^{b c}$ & $270^{a}$ & $317^{\mathrm{ab}}$ & $298^{\mathrm{ab}}$ & 15.5 & 0.772 & $<0.001$ & 0.015 \\
\hline serine & $240^{b}$ & $333^{c}$ & $194^{\mathrm{ab}}$ & $221^{\mathrm{ab}}$ & $153^{\mathrm{a}}$ & $169^{a b}$ & $215^{\mathrm{ab}}$ & $246^{b}$ & 11.3 & 0.034 & 0.002 & 0.472 \\
\hline tyrosine & $196^{c}$ & $243^{d}$ & $108^{a}$ & $149^{b}$ & $83.3^{a}$ & $89.9^{a}$ & $108^{a}$ & $107^{a}$ & 9.80 & 0.007 & $<0.001$ & 0.095 \\
\hline \multicolumn{13}{|l|}{ Others, $\mu \mathrm{mol} / /$} \\
\hline taurine & $136^{\mathrm{a}}$ & $234^{c}$ & $156^{\mathrm{ab}}$ & $207^{\mathrm{bc}}$ & $202^{\mathrm{bc}}$ & $240^{\circ}$ & $224^{c}$ & $197^{\mathrm{bc}}$ & 8.14 & 0.004 & 0.088 & 0.021 \\
\hline ornithine & $125^{d}$ & $131^{d}$ & $64.8^{\mathrm{ab}}$ & $75.9^{\mathrm{abc}}$ & $48.2^{\mathrm{a}}$ & $48.3^{a}$ & $86.2^{\mathrm{bc}}$ & $93.8^{c}$ & 5.63 & 0.321 & $<0.001$ & 0.946 \\
\hline urea & $2183^{\mathrm{ab}}$ & $1687^{a}$ & $3623^{b c}$ & $638^{a}$ & $3639^{b c}$ & $5055^{c}$ & $5365^{c}$ & $4257^{c}$ & 317 & 0.065 & $<0.001$ & 0.008 \\
\hline ammonia & $725^{\mathrm{abc}}$ & $692^{\mathrm{ab}}$ & $479^{a}$ & $495^{\mathrm{a}}$ & $974^{\text {cd }}$ & $927^{\text {bcd }}$ & $892^{\text {bcd }}$ & $1066^{d}$ & 44.9 & 0.659 & $<0.001$ & 0.568 \\
\hline
\end{tabular}

${ }_{1}^{1}$ data are expressed as mean for ten piglets per treatment; ${ }^{2}$ groups: $7 \mathrm{~h}, 3 \mathrm{~d}, 6 \mathrm{~d}$ and $9 \mathrm{~d}$ - treatment duration: $7 \mathrm{~h}$ and 3,6 and 9 days, respectively; $\mathrm{C}$ - control (no spermine supplementation); S - spermine supplementation at a dose of $0.4 \mathrm{mmol} / \mathrm{kg}$ body weight; ${ }^{\text {a-d }}$ - means within different superscripts are significantly different $(P<0.05)$

group (C-6d) it was higher than in the C-7h. His and regardless spermine addition. The comparison of Tau content did not differ in S-6d and S-7h groups, 7-h and 9-day experiments showed that His and but in the C-6d it was increased in comparison to the Tau content did not differ between S-7h and S-9d C-7h. Phe, Asp and Pro contents were decreased and but in the case of comparison of control groups urea content was increased in the S-6d group, while (C-7h vs C-9d) an increase was observed. between control groups there was no difference. The Phe content was decreased in the S-9d but increased contents of Lys, Thr, Ala and Tyr were decreased in the C-9d in comparison to respective 7-h groups. in 6-day experiment in comparison to 7-h one Asp and Glu contents were increased after 9 days

Table 4. Effects of spermine supplementation (S) and time of its duration $(T)$ on the mRNA levels for select amino acid transporters in ileum of piglets $^{1}$

\begin{tabular}{|c|c|c|c|c|c|c|c|c|c|c|c|c|}
\hline \multirow{2}{*}{ Gene } & \multicolumn{2}{|l|}{$7 h^{2}$} & \multicolumn{2}{|l|}{$3 d$} & \multicolumn{2}{|l|}{$6 d$} & \multicolumn{2}{|l|}{$9 d$} & \multirow{2}{*}{ SEM } & \multicolumn{3}{|l|}{$P$-value } \\
\hline & C-7h & S-7h & $C-3 d$ & $S-3 d$ & C-6d & S-6d & C-9d & $S-9 d$ & & $S$ & $T$ & $S \times T$ \\
\hline SLC1A1 & $1.00^{\mathrm{ab}}$ & $0.872^{\mathrm{ab}}$ & $0.691^{a}$ & $2.82^{\mathrm{d}}$ & $0.944^{\mathrm{ab}}$ & $1.80^{\circ}$ & $1.21^{b}$ & $1.59^{c}$ & 0.102 & $<0.001$ & $<0.001$ & $<0.001$ \\
\hline SLC1A5 & $1.00^{\mathrm{bc}}$ & $1.43^{\mathrm{d}}$ & $1.01^{\mathrm{c}}$ & $1.18^{\text {cd }}$ & $1.08^{c}$ & $2.09^{e}$ & $0.674^{a}$ & $0.787^{a b}$ & 0.066 & $<0.001$ & $<0.001$ & $<0.001$ \\
\hline SLC7A1 & $1.00^{\circ}$ & $1.06^{c}$ & $0.902^{b c}$ & $1.10^{c}$ & $0.936^{b c}$ & $1.61^{d}$ & $0.599^{a}$ & $0.802^{a b}$ & 0.046 & $<0.001$ & $<0.001$ & $<0.001$ \\
\hline SLC7A7 & $1.00^{\mathrm{cd}}$ & $0.699^{b}$ & $0.590^{\mathrm{ab}}$ & $2.00^{e}$ & $0.482^{\mathrm{a}}$ & $1.18^{d}$ & $0.895^{\circ}$ & $1.11^{\mathrm{d}}$ & 0.068 & $<0.001$ & $<0.001$ & $<0.001$ \\
\hline SLC7A9 & $1.00^{c}$ & $1.14^{\text {cd }}$ & $0.832^{b}$ & $1.99^{f}$ & $0.647^{a}$ & $1.63^{e}$ & $1.29^{d}$ & $1.29^{d}$ & 0.062 & $<0.001$ & $<0.001$ & $<0.001$ \\
\hline SLC5A1 & $1.00^{\mathrm{ab}}$ & $0.806^{a}$ & $1.13^{b}$ & $4.00^{f}$ & $1.37^{c}$ & $2.01^{\mathrm{d}}$ & $1.12^{\mathrm{b}}$ & $2.50^{\mathrm{e}}$ & 0.149 & $<0.001$ & $<0.001$ & $<0.001$ \\
\hline SLC6A19 & $1.00^{\mathrm{b}}$ & $1.05^{b}$ & $0.990^{b}$ & $1.52^{c}$ & $0.562^{\mathrm{a}}$ & $1.24^{b}$ & $1.03^{b}$ & $0.969^{b}$ & 0.048 & $<0.001$ & 0.006 & $<0.001$ \\
\hline SLC15A1 & $1.00^{\mathrm{b}}$ & $1.21^{\mathrm{bc}}$ & $1.07^{\mathrm{b}}$ & $2.47^{\mathrm{e}}$ & $0.717^{a}$ & $1.83^{d}$ & $1.45^{c}$ & $1.45^{c}$ & 0.081 & $<0.001$ & $<0.001$ & $<0.001$ \\
\hline
\end{tabular}

${ }^{1}$ data are expressed as mean for ten piglets per treatment; ${ }^{2}$ groups: $7 \mathrm{~h}, 3 \mathrm{~d}, 6 \mathrm{~d}$ and $9 \mathrm{~d}-$ treatment duration: $7 \mathrm{~h}$ and 3,6 and 9 days, respectively; $\mathrm{C}$ - control (no spermine supplementation); $\mathrm{S}$ - spermine supplementation at a dose of $0.4 \mathrm{mmol} / \mathrm{kg}$ body weight; ${ }^{\text {a-f }}$ - means within different superscripts are significantly different $(P<0.05)$ 
of spermine supplementation but not when control treatment was used. The contents of Thr, Ala and Tyr were decreased in 9-day experiment in comparison to 7-h one regardless spermine addition.

\section{Gene expression in ileum of piglets}

In comparison to control treatment, in the $\mathrm{S}-7 \mathrm{~h}$ group the gene expression of SLC1A5 was increased and $S L C 7 A 7$ decreased in ileum of piglets (Table 4). In the 3-day experiment there was stated an increase in gene expression of SLC1A1, SLC7A7, SLC7A9, SLC5A1, SLC6A19 and SLC15A1. When supplementation lasted for 6 days, the mRNA levels of all examined amino acids transporters were increased in comparison to control group. On the other hand in the 9-day experiment the difference between S-9d and C-9h was stated only for the SLC1A1, SLC7A7 and SLC5A1 gene expression.

When the duration of supplementation was compared, it was stated that in comparison to the $\mathrm{S}-7 \mathrm{~h}$ group, the 3-day spermine supplementation caused an increase in gene expression of SLCA1, SLC5A1, SLC6A19 and SLC15A1 $(P<0.05)$, while there was no difference between 7-h and 3-day control groups. The increase in the S-3d group was also observed for SLC7A7 and SLC7A9 but for the control group there was stated a decrease. When the 6-day experiment was compared to 7-h one, the expression of genes encoding SLC1A1, SLC1A5, SLC7A1 was increased in spermine-treated group, but not when control groups were compared. After 9 days of the experiment, the gene expression was still higher than in the S-7h group for SLC1A1, SLC7A1 and SLC5A1, while in the control group mRNA levels of these genes were the same as in the $\mathrm{C}-7 \mathrm{~h}$. On the other hand the mRNA levels of SLC7A9 and SLC15A1 were similar in $\mathrm{S}-9 \mathrm{~d}$ and $\mathrm{S}-7 \mathrm{~h}$ groups, while they were higher in the C-9d group in comparison to the C-7h one.

\section{Discussion}

In the intestines spermine regulates gene expression, postnatal maturation, antioxidant capacity, nutrient absorption and metabolic pathways (Cao et al., 2015; Liu et al., 2015; Fang et al., 2016). Thus, spermine has been recognized as a nutritional substance for young mammals, including piglets (Fang et al., 2017). Notably, in many reports it has been shown that dietary supplementation with spermine may play an important role in the alleviating inflammatory response, enhancing the immune function and systemic metabolic modifications on animal growth (Liu et al., 2015; Cao et al., 2017). In the present study, all piglets were growing up healthy with normal feed intake and body weight gain, and spermine supplementation promoted the growth and maturation of ileal structures, and improved digestive and absorptive functions by increasing the specific activities of sucrase and maltase in the ileum (Fang et al., 2016). Meanwhile, spermine supplementation also promoted antioxidant defence in serum by increasing free-radical scavenging capacities and enzymatic and non-enzymatic antioxidant capacities (Fang et al., 2016).

The obtained results show that spermine supplementation exerts influence on serum AST activity and TG and ALB levels in piglets. This finding suggests that spermine supplementation can cause changes in serum biochemistry variables, however the duration of supplementation may have a critical role. Reportedly, AST and ALT enzymes in serum are sensitive indicators of liver cells (hepatocytes) (Thapa and Walia, 2007). Moreover, TG and CHO were examined in the present study. The obtained results reveal that piglets supplied with spermine have lower serum TG level in comparison to the control group, which indicates that supplementation with spermine may affect lipid metabolism. However, such a result is inconsistent with the results of Liu et al. (2014a), who reported that spermine significantly increased the TG levels in weaned rats under stressful conditions. In the Liu's experiment, rats received spermine supplementation and intraperitoneally diquat injection; on the other hand in the present study piglets were only supplemented with spermine (no stress was induced). The next examined serum biochemical parameters were the contents of TP and ALB. Proteins are fundamental components of all living cells, and the serum levels of TP and ALB represent the changes in protein biosynthesis or metabolism. The increase in ALB suggests that spermine may promote protein synthesis by altering protein metabolism. Such increase also indicates an improvement in the efficiency of dietary protein utilization. Proteins are the main component of cells and tissues of the body, and the increase in ALB means that spermine may maintain the structural integrity of the internal organ.

In the present study it was shown that extended spermine supplementation can affect biochemical parameters in the serum. Furthermore, spermine supplementation for 3 days increased ALB and BUN but decreased $\mathrm{CHO}$ as compared to those observed after $7 \mathrm{~h}$ of spermine treatment. The increase in ALB and BUN indicates that the 3 days of spermine 
treatment may modulate the utilization efficiency of dietary protein. This response may be partly due to the thyroid hormones, which are required for stimulation of urea cycle enzymes (Murray, 2009); however, the underlying mechanisms require future investigations.

Since protein metabolism is often associated with changes in serum amino acids, the effect of spermine supplementation and its duration on the serum profile of amino acid profile was investigated in this study. Amino acids play an important role in the organism's functioning. The results obtained in the present study show that dietary supplementation with spermine caused a marked enhancement in the levels of essential and non-essential amino acids. The results obtained in the present study are similar to those reporting that spermine can increase the levels of plasma Tyr, Leu and Val in weaned rats (Liu et al., 2014b). These data indicate that spermine supplementation is a viable nutritional strategy for raising the concentration of essential amino acids or non-essential amino acids in piglets. Among essential amino acids, Arg is stated to play an important function in the regulation of growth and metabolic process and to serve as a physiologically important up-stream metabolic product of spermine in pigs (Pollack et al., 1992). Furthermore, Ile, Leu and Val are branched-chain amino acids (Lin et al., 2002) performing nutritional and regulatory functions in energy-generating metabolism. The increase in branched-chain amino acid level may further indicate increased energy expenditure during liver weight gain in spermine piglets while the liver is the main metabolic organ in the body. Moreover, available evidence shows that Arg and Leu increase the expression of amino acid transporters by stimulating the phosphorylation of mTOR in a cell-specific manner, which regulates intracellular protein turnover $(\mathrm{Wu}, 2009)$. Thus, the increased Arg and Leu levels in serum may be the prediction that spermine can regulate protein turnover by indirectly activating mTOR signalling pathway (Fang et al., 2017).

In the current study, it was observed that the 7-h spermine supplementation resulted in high levels of essential amino acids, such as Arg, His, Leu and Val. The effect of extended spermine supplementation on essential amino acid reveals that prolonged spermine supplementation can distinctively affect essential amino acids. Such an effect may be partially due to a depressed availability of ammonia as a result of reinforced protein synthesis and reduced oxidation of amino acids. This finding can be supported by the lower concentrations of urea and ammonia in the 3-day spermine supplemented group. Low concentrations of urea and ammonia represent a high rate of protein synthesis and a low rate of amino acid catabolism (Nicklin et al., 2009). Interestingly, the observed high rates of protein synthesis may entirely account for the increase in organ weight. The 3-day spermine supplementation resulted in heavier relative organ weight (such as heart, liver, kidney, spleen, pancreas and thymus) in comparison to those observed after $7 \mathrm{~h}, 6$ and 9 days of spermine treatment (data not shown). This result coincides with a decrease in essential amino acids in the serum. However, unlike essential amino acids, non-essential amino acids (such as Asp, Ser and Tyr) content was lower in the 6-day spermine supplemented group than in the group with 7-h spermine supplementation. Non-essential amino acids are amino acids that can be synthesized by the body to satisfy optimal requirements. The reduction of non-essential amino acids may be attributed to the increase in essential amino acids induced by the 6-day spermine supplementation. No research has been conducted on the possible effects of spermine on essential and non-essential amino acids in piglets. The mechanism by which spermine mediates changes in amino acid profile needs further investigation. Moreover, the concentration of amino acids in serum is strictly connected with their absorption from the intestines involving amino acid transporters located in the enterocyte membrane (Wu, 2010). On this basis, we investigated the influence of dietary supplementation with spermine and its extended supplementation on the expression of genes encoding ileum amino acid transporters.

Amino acids are transported mainly into intestinal epithelial cells via numerous transporter systems; intestinal transporters of amino acids vary in type and capacity and overlap in specificity (Bröer, 2008). SLC1A1 is a high-affinity Glu transporter that can mediate the cellular uptake of Glu and sustain Glu concentration gradients across membranes. SLC1A5 and SLC6A19 are two major neutral amino acid transporters that can facilitate the electroneutral exchange of Ala, Ser, Cys, Thr, Gln and Asp using the cotransport of $\mathrm{Na}^{+}$as an energy source for substrate translocation in the intestine (Grewer et al., 2014). The results of the present study show that dietary supplementation with spermine enhances the expression of SLC1A1, SLC1A5 and SLC6A19 transporters in the ileum. Therefore, spermine can improve the absorptive efficiency of glutamate and neutral amino acids in the ileum in 
piglets. In addition, SLC5A1 is a sodium-coupled GLU cotransporter and performs a central function in intestinal GLU absorption (Wright et al., 2007). The increased expression of SLC5A1 may suggest that spermine can facilitate the equilibration of sugar across the brush border membrane of the ileum. Correlation analysis showed that SLC1A1 mRNA level was positively related to SLC5A1 and SLC6A19 mRNA levels $\left(r_{\mathrm{SLC5A1}}=+0.950, P_{\mathrm{SLC5A1}}<0.01 ; r_{\mathrm{SLC} 6 \mathrm{~A} 19}\right.$ $\left.=+0.774, P_{\mathrm{SLC6A} 19}<0.05\right)$, suggesting that spermineincreased SLCIA1 mRNA level may partially ascribe to up-regulate SLC5A1 and SLC6A19 mRNA expressions in the ileum of piglets.

Cationic amino acid transporter SLC7A1 and the L-type amino acid transporters SLC7A7 and SLC7A9 are two subgroups of the SLC7 family (Verrey et al., 2004). SLC7A7 and SLC7A9 selectively transport neutral amino acids (amino acid transport system L and Asc, Ala, Ser and Cys), aromatic amino acids (Tyr, Phe and Try) and negatively charged amino acid (system $x_{c}^{-}$) (Fotiadis et al., 2013). The results of the current study show that supplementation with spermine can increase mRNA levels of SLC7A1, $S L C 7 A 7$ and SLC7A9. Therefore, spermine is crucial for ileum protein synthesis and metabolic regulation. These results are similar to a finding reporting that dietary Arg supplementation can enhance ileal expression of SLC7A1 and SLC7A7 (Yin et al., 2013). SLC15A1 represents a family of intestinal proton-oligopeptide transporters, which mediate the uptake of peptide substrates into intestinal epithelial cells (Daniel and Kottra, 2004). In the current study, we observed that spermine significantly increased the expression of ileal $S L C 15 A 1$ in piglets. An increase in the SLC15A1 may enhance oligopeptide synthesis. However, the underlying mechanisms require further investigation.

Moreover, our study shows that 3-day spermine supplementation caused an increase in mRNA levels of SLC1A1, SLC5A1, SLC7A7, SLC6A19, and $S L C 15 A 1$ in comparison to 7-h administration. These changes can be associated with the changes in serum amino acid concentrations. The degradation of expression levels of amino acid transporters in the ileum by prolonged spermine supplementation can increase amino acid concentrations in serum. However, further studies are needed to examine the relationship between gene regulation of amino acid transporters in the ileum and amino acid concentrations in serum, which are induced by spermine supplementation. Importantly, the mRNA level of SLC6A19 was markedly increased in the 3-day spermine supplementation but notably decreased in the 9-day one. These contrasting changes of expression of ileal amino acid transporters may be partially due to the following reasons: (1) spermine exerts only a short-term effect on the gene expression of ileal amino acid transporters; this observation is consistent with the results of our previous studies, indicating that spermine exerts better effect on facilitating ileum growth after 3 days of treatment than after 9-day supplementation (Fang et al., 2016); (2) gene expression induced by spermine may decrease along with the pig's age because the ileum may become insensitive to spermine with increasing age.

\section{Conclusions}

Spermine supplementation affects serum biochemical parameters as well as essential and nonessential amino acids profile, and may alter the ileal absorption of amino acids by promoting the expression of amino acid transporters in the ileum, although the duration of spermine supplementation is an important factor. Thus, spermine may be a beneficial supplement in piglets feeding. However, further studies to reveal the mechanism underlying the effect of spermine supplementation on protein synthesis are needed.

\section{References}

Bröer S., 2008. Amino acid transport across mammalian intestinal and renal epithelia. Physiol. Rev. 88, 249-286, https://doi. org/10.1152/physrev.00018.2006

Cao W., Liu G., Fang T., Wu X., Jia G., Zhao H., Chen X., Wu C., Wang J., Cai J., 2015. Effects of spermine on the morphology, digestive enzyme activities, and antioxidant status of jejunum in suckling rats. RSC Adv. 5, 76607-76614, https://doi.org/10.1039/ C5RA15793E

Cao W., Wu X., Jia G., Zhao H., Chen X., Wu C., Tang J., Wang J., Cai J., Liu G., 2017. New insights into the role of dietary spermine on inflammation, immune function and related-signalling molecules in the thymus and spleen of piglets. Arch. Anim. Nutr. 71, 175-191, https://doi.org/10.1080/1745039x.2017.1314610

Cheng Z.B., Li D.F., Xing J.J., Guo X.Y., Li Z.J., 2006. Oral administration of spermine advances intestinal maturation in sucking piglets. Anim. Sci. 82, 621-626, https://doi.org/10.1079/ASC200690

Closs E.I., Boissel J.-P., Habermeier A., Rotmann A., 2006. Structure and function of cationic amino acid transporters (CATs). J. Membrane Biol. 213, 67-77, https://doi.org/10.1007/s00232006-0875-7

Daniel H., Kottra G., 2004. The proton oligopeptide cotransporter family SLC15 in physiology and pharmacology. Pflügers Arch. 447, 610-618, https://doi.org/10.1007/s00424-003-1101-4

Fang T., Liu G., Cao W., Wu X., Jia G., Zhao H., Chen X., Wu C., Wang J., 2016. Spermine: new insights into the intestinal development and serum antioxidant status of suckling piglets. RSC Adv. 6, 31323-31335, https://doi.org/10.1039/ C6RA05361K 
Fang T., Zheng J., Cao W., Jia G., Zhao H., Chen X., Cai J., Wang J., Liu G., 2017. Effects of spermine on the antioxidant status and gene expression of antioxidant-related signaling molecules in the liver and longissimus dorsi of piglets. Animal 12, 1208-1216, https://doi.org/10.1017/S1751731117002737

Fotiadis D., Kanai Y., Palacín M., 2013. The SLC3 and SLC7 families of amino acid transporters. Mol. Aspects Med. 34, 139-158, https://doi.org/10.1016/j.mam.2012.10.007

Grewer C., Gameiro A., Rauen T., 2014. SLC1 glutamate transporters. Pflügers Arch. 466, 3-24, https://doi.org/10.1007/s00424013-1397-7

Hougaard D.M., Nielsen J.H., Larsson L.I., 1986. Localization and biosynthesis of polyamines in insulin-producing cells. Biochem. J. 238, 43-47, https://doi.org/10.1042/bj2380043

Larqué E., Sabater-Molina M., Zamora S., 2007. Biological significance of dietary polyamines. Nutrition $23,87-95$, https://doi.org/10.1016/j.nut.2006.09.006

Lin C.-H., Vijesurier R., Ho Y.-S., Schipper R.G., Tolia V., Moshier J.A. Majumdar A.P.N., 2002. Expression of intestinal ornithine decarboxylase during postnatal development in neonatal rats. Biochim. Biophys. Acta 1589, 298-304, https://doi. org/10.1016/S0167-4889(02)00177-5

Liu G., Fang T., Yan T., Jia G., Zhao H., Chen X., Wu C., Wang J., 2014a. Systemic responses of weaned rats to spermine against oxidative stress revealed by a metabolomic strategy. RSC Adv. 4, 56766-56778, https://doi.org/10.1039/ c4ra09975c

Liu G., Fang T., Yan T., Jia G., Zhao H., Huang Z., Chen X., Wang J., Xue B., 2014b. Metabolomic strategy for the detection of metabolic effects of spermine supplementation in weaned rats. J. Agric. Food Chem. 62, 9035-9042, https://doi. org/10.1021/j5500882t

Liu G., Yan T., Fang T., Jia G., Chen X., Zhao H., Wang J., Wu C., 2015. Nutrimetabolomic analysis provides new insights into spermine-induced ileum-system alterations for suckling rats. RSC Adv. 5, 48769-48778, https://doi.org/10.1039/ C5RA01507C

Livak K.J., Schmittgen T.D., 2001. Analysis of relative gene expression data using real-time quantitative PCR and the $2-\triangle \Delta C T$ method. Methods 25, 402-408, https://doi.org/10.1006/ meth.2001.1262
Murray R.K., 2009. Harper's Illustrated Biochemistry. McGraw-Hill Medical. New York, NY (USA)

Nicklin P., Bergman P., Zhang B. et al., 2009. Bidirectional transport of amino acids regulates mTOR and autophagy. Cell 136, 521-534, https://doi.org/10.1016/j.cell.2008.11.044

Pegg A.E., 2014. The function of spermine. IUBMB Life $66,8-18$, https://doi.org/10.1002/iub.1237

Pollack P.F., Koldovskỳ O., Nishioka K., 1992. Polyamines in human and rat milk and in infant formulas. Am. J. Clin. Nutr. 56, 371-375, https://doi.org/10.1093/ajcn/56.2.371

Rutherfurd S.M., Gilani G.S., 2009. Amino acid analysis. Curr. Protoc. Protein Sci. 58, 11.9.1-11.9.37, https://doi. org/10.1002/0471140864.ps1109s58

Southern L.L., Baker D.H., 1982. Performance and concentration of amino acids in plasma and urine of young pigs fed diets with excesses of either arginine or lysine. J. Anim. Sci. 55, 857-866, https://doi.org/10.2527/jas1982.554857x

Taylor P.M., 2014. Role of amino acid transporters in amino acid sensing. Am. J. Clin. Nutr. 99, 223S-230S, https://doi. org/10.3945/ajcn.113.070086

Thapa B., Walia A., 2007. Liver function tests and their interpretation. Indian J. Pediatr. 74, 663-671, https://doi.org/10.1007/ s12098-007-0118-7

Verrey F., Closs E.I., Wagner C.A., Palacin M., Endou H., Kanai Y., 2004. CATs and HATs: the SLC7 family of amino acid transporters. Pflügers Arch. 447, 532-542, https://doi. org/10.1007/s00424-003-1086-z

Wright E.M., Hirayama B.A., Loo D.F., 2007. Active sugar transport in health and disease. J. Intern. Med. 261, 32-43, https://doi. org/10.1111/j.1365-2796.2006.01746.x

Wu G., 2009. Amino acids: metabolism, functions, and nutrition. Amino Acids 37, 1-17, https://doi.org/10.1007/s00726-009-0269-0

Wu G., 2010. Functional amino acids in growth, reproduction, and health. Adv. Nutr. 1, 31-37, https://doi.org/10.3945/ an. 110.1008

Yin J., Ren W., Duan J., Wu L., Chen S., Li T., Yin Y., Wu G., 2013. Dietary arginine supplementation enhances intestinal expression of SLC7A7 and SLC7A1 and ameliorates growth depression in mycotoxin-challenged pigs. Amino Acids 46, 883-892, https://doi.org/10.1007/s00726-013-1643-5 